\title{
Sistema de indicadores de sustentabilidade do desenvolvimento do turismo: um estudo de caso do município de Areia - PB
}

\author{
Sustainability indicators system of tourism development: a case \\ study os the municipality of Areia - PB
}

\section{Sistema de indicadores de sostenibilidad del desarrollo del turismo: un estudio de caso del município de Areia - PB}

\author{
Nicole Cavalcanti Silva ${ }^{1}$ \\ Gesinaldo Ataíde Cândido²
}

\begin{abstract}
Resumo: $\mathrm{O}$ objetivo deste artigo é identificar e analisar o nível de sustentabilidade da atividade turística no município de Areia - PB, através de aplicação da metodologia do Sistema de Indicadores de Sustentabilidade do Desenvolvimento do Turismo (SISDTur), proposto por Hanai (2009). A pesquisa caracteriza-se como descritiva e exploratória, de natureza quantitativa, complementada por análise de dados secundários e observação não participante. Foram estabelecidos três estágios de critérios de análises dos dados: análise dos indicadores, onde os dados coletados foram tratados por meio de técnicas estatísticas: média, desvio-padrão e coeficiente de variação; análise das dimensões e análise global da sustentabilidade. Os resultados obtidos apontam que o município pesquisado apresenta-se parcialmente insustentável, comprovada pela faixa do padrão de sustentabilidade e insustentabilidade, pois das seis dimensões da sustentabilidade duas apresentaram-se em sustentabilidade intermediária, duas parcialmente insustentáveis e duas insustentáveis. Tal situação demanda novas e melhores formas de atuação dos gestores públicos na implementação de investimentos, planos e projetos que possam viabilizar a sua melhoria e contribuir com o desenvolvimento sustentável do turismo no município.
\end{abstract}

Palavras-chave: Turismo. Indicadores de sustentabilidade. Desenvolvimento sustentável. Areia - PB.

Abstract: This article aims at identifying and analyzing the level of sustainability of tourism in the city of Areia $P B$, by applying the methodology of the Sustainability Indicators System of Tourism Development (SISDTur) proposed by Hanai (2009). This work is descriptive and it presents an exploratory and quantitative research. To carry out this investigation, three stages of data analysis criteria were established: analysis of indicators, in which the collected data were processed by statistical techniques (average, standard deviation and coefficient of variation); analysis of dimensions; and analysis of global sustainability. The results indicate that the municipality presents a partly unsustainable tourism, since among the six sustainability dimensions for tourism destinations two dimensions demonstrate intermediary sustainability, two dimensions are partially unsustainable, and the other two

${ }^{1}$ Universidade Federal de Campina Grande (UFCG), Campina Grande, PB, Brasil
${ }^{2}$ Universidade Federal de Campina Grande (UFCG), Campina Grande, PB, Brasil

Rev. Bras. Pesq. Tur. São Paulo, 10(3), pp. 475-496, set./dez. 2016. 
dimensions are unsustainable. This situation demands from public administrators the design of new action plans for the implementation of investments and projects that may facilitate the sustainable development of tourism in the municipality.

Keywords: Tourism. Indicators of sustainability. Sustainable Development. Areia - PB.

Resumén: El propósito de este artículo es identificar y analizar el nivel de sostenibilidad del turismo en el municipio de Areia - PB, aplicando la metodología del Sistema de Indicadores de Sostenibilidad del Desarrollo del Turismo (SISDTUr), propuesto por Hanai (2009). La investigación se caracteriza por ser descriptivo y exploratorio, cuantitativo, el análisis completo de los datos secundarios y observación no participante. Se establecieron tres etapas de criterios de análisis de datos: El análisis de los indicadores de que los datos recogidos se analizaron por medio de técnicas estadísticas: media, desviación estándar y coeficiente de variación; Análisis de las dimensiones; Información general y de la sostenibilidad. Los resultados indican que el municipio ha investigado en parte insostenible, lo demuestra la gama estándar de sostenibilidad y la insostenibilidad a causa de las seis dimensiones de la sostenibilidad de dos presentados en la sostenibilidad intermedia, dos parcialmente insostenibles, y dos insostenible. Esta situación exige nuevas y mejores formas de trabajar de los gestores públicos en la ejecución de los planes de inversión y proyectos que pueden facilitar su mejora y contribuir al desarrollo sostenible del turismo en el municipio.

Palabras clave: Turismo. Indicadores de sostenibilidad. Desarrollo sostenible. Areia - PB.

\section{INTRODUÇÃO}

O turismo é o fenômeno econômico mais expressivo das últimas décadas, apresentando-se atualmente como uma das áreas econômicas com maior potencial de geração de riqueza, desenvolvimento, competitividade e importância estratégica da atualidade, em alguns casos o turismo é a mais importante fonte de renda de uma região, constituindo-se em um fator potencial de desenvolvimento aliado no combate e minimização da pobreza de uma dada localidade (Rodrigues, 1999; Beni, 2002; Braga, 2007).

Segundo o Ministério do Turismo e de acordo com os dados do Conselho Mundial de Viagens e Turismo - WTTC (2014), sobre o impacto do turismo no mundo, o Brasil aparece em sexto lugar no ranking entre as economias do turismo no mundo. Diante da expressiva contribuição do desenvolvimento do turismo proporcionado a uma dada economia local e dos impactos ambientais positivos e negativos decorrentes dessa atividade, torna-se necessário conhecer e estimular atividades de gestão dos recursos naturais e de outras ferramentas de educação ambiental e empresarial nas empresas do setor turístico, visando atender à demanda e também a minimizar os impactos ambientais decorrentes da exploração dessa atividade.

Nesse sentido, Santos e Cândido (2015), ressaltam que as atividades desenvolvidas em uma dada localidade devem atender aos princípios da sustentabilidade para manter o equilíbrio e a equidade entre as dimensões ambiental, social e econômica, contando com o engajamento dos diversos atores sociais para o planejamento e a execução de ações que possam contribuir para tal alcance, uma vez que, o turismo, como uma atividade que impacta, positiva e negativamente, a localidade que a desenvolve, deve ser gerenciado a partir do equilíbrio e da equidade entre as dimensões supracitadas. 
O estado da Paraíba apresenta muitas riquezas naturais e histórico-culturais que formam um produto turístico bem diversificado que tem contribuído para o desenvolvimento socioeconômico da região e do Estado, porém esta atividade tem sido desenvolvida de forma precária nas regiões que foram mapeadas pelo Programa de Regionalização do Turismo desenvolvido pelo Governo Federal, pois não existe, na maioria dos casos, um plano de ação integrado das instituições e empreendimentos que trabalham nesse segmento.

Como lócus de pesquisa, foi feito um estudo no destino turístico município de Areia $\mathrm{PB}$, situada na região do brejo paraibano, sendo conhecido nacionalmente e internacionalmente por sua produção de aguardente (cachaça), açúcar e rapadura. Além disso, a atividade turística vem sendo explorada a atividade turística mais intensamente, após seu tombamento e inclusão nos roteiros turísticos do brejo paraibano, a exemplo do turismo ecológico, rural, cultural, de aventura, de eventos e gastronômico caracterizado pelo rico patrimônio natural, histórico e cultural da cidade e região, composto por igrejas, solares, teatros, restaurantes, engenhos, sobrados, museus, casarões e casas de farinha. No turismo ecológico, rural e de aventura o destaque vai para os engenhos abertos à visitação turística, trilhas ecológicas e acesso a balneários, além de um diversificado artesanato e comidas típicas regionais (Areia, 2015).

O município foi escolhido para realização desta pesquisa por ser potencialmente turístico pelo Programa da Regionalização do Turismo do Governo Federal após seu tombamento, e porque embora sendo um município essencialmente rural e agrário tem um grande potencial turístico a ser explorado, porém poucos planos e projetos foram desenvolvidos na área de turismo sustentável e poucos estudos metodológicos foram implementados com foco no desenvolvimento sustentável na área de turismo nessa localidade razões, estas, que justificam a realização da presente pesquisa.

Para os fins do estudo e pesquisa realizada, foi adaptada uma metodologia do Sistema de Indicadores de Sustentabilidade do Desenvolvimento do Turismo (SISDTur), proposto por Hanai (2009), que consiste em um sistema de indicadores de sustentabilidade composto por seis dimensões, com seus respectivos indicadores de sustentabilidade selecionados, hierarquizados e ponderados a partir da participação da comunidade local. Este modelo também foi escolhido por ser consistente e apresentar critérios de seleção dos indicadores, parâmetros e critérios de análises específicos para a análise dos dados e para o desenvolvimento desse trabalho.

A partir destas considerações iniciais, o objetivo do artigo é identificar o nível de sustentabilidade da atividade turística de Areia-PB, depois da caracterização do município e de suas atividades turísticas. Em termos metodológicos, foi realizado um estudo de abordagem quantitativa, exploratório e descritivo, conduzido sob a forma de um estudo de caso realizado em Areia-PB. A coleta dos dados se deu a partir da aplicação de questionários junto aos atores 
sociais que compõem o trade turístico do município, poder público, iniciativa privada e sociedade civil que lidam direta e indiretamente com as atividades turísticas, além da observação não participante durante o período de coleta de dados.

No que diz respeito à sua estrutura, o artigo está dividido em cinco seções: além desta introdução; a segunda seção traz um levantamento teórico capaz de subsidiar a pesquisa ao longo de seu desenvolvimento; na terceira seção, são apresentados os procedimentos metodológicos; a seguir, a apresentação e análise dos resultados e, por fim, as considerações finais.

\section{REFERENCIAL TEÓRICO}

\subsection{Desenvolvimento Sustentável e Atividade Turística}

A primeira definição de Desenvolvimento Sustentável foi consolidada a partir do Relatório Brunddtland, em 1987, que definia desenvolvimento sustentável como sendo aquele que atende às necessidades das gerações presentes sem comprometer a capacidade das gerações futuras em atenderem suas próprias necessidades. Nessa perspectiva, a Organização Mundial de Turismo (2003), defende que o turismo sustentável é o que relaciona as necessidades dos turistas com as das gerações receptoras, protegendo e fortalecendo oportunidades para o futuro.

O Ministério do Turismo (2007) frisa que sustentabilidade no turismo consiste em um processo contínuo e requer constante previsão de tendências e monitoramento dos impactos para a introdução de medidas preventivas ou corretivas quando necessário, de forma que, respeite o potencial e o limite natural da localidade a ser desenvolvida turisticamente. Assim, o turismo sustentável contempla o planejamento e a gestão dos recursos naturais, econômicos, sociais e das necessidades estéticas, mantendo a integridade cultural, os processos ecológicos essenciais, a diversidade biológica e os sistemas de suporte à vida (OMT, 2003).

Para Lage e Milone (2009) apud Silva et al. (2013), para a prática do turismo é necessário haver o produto turístico, formado pelo conjunto de bens e serviços, e abrange: o transporte, a alimentação, a acomodação e o entretenimento, cabendo aos gestores públicos e privados seu devido planejamento para que seu desenvolvimento esteja atrelado aos princípios da sustentabilidade.

Segundo Gomes (2009), a estrutura do turismo é composta pelos meios de hospedagem, restaurantes, bares, entretenimento, agências de turismo, guias de turismo e agências de viagem, dentre outros. Esse conjunto de empresas para Souza e Ferreira (2011), tem como objetivo aumentar o fluxo de pessoas que se deslocam para determinada área receptora, 0 seu grau de participação nas atividades de recreação, da oferta de unidades de alojamento, taxas de ocupação dessas unidades, taxas de visitação e uso, dentre outros, com a finalidade de obter lucro. 
Nesse aspecto, as organizações que assumem uma postura ética na prestação dos produtos ou serviços turísticos contribuem para o alcance de uma imagem positiva diante dos seus concorrentes, podendo tornar, esta, uma vantagem competitiva empresarial, visto que os turistas se mostram interessados num turismo social e ambientalmente responsável (Virginio \& Fernandes, 2011).

Molina (2011) destaca que os turistas atualmente estão selecionando os destinos turísticos a partir de critérios da análise da qualidade ambiental e dos níveis de ruídos e densidade dos lugares que irão visitar. Nesse sentido, as empresas do setor turístico precisam trabalhar em conjunto, de forma engajada, de modo a oferecer aos turistas um serviço ou produto turístico que atenda aos princípios da sustentabilidade e, ao mesmo tempo, satisfaça os anseios dos mesmos.

Santos e Cândido (2013), afirmam que planejar e executar a atividade turística considerando os princípios da sustentabilidade se caracteriza como uma oportunidade para diversos atores envolvidos, visto que as empresas apresentam um compromisso com os stakeholders (acionistas, funcionários, prestadores de serviços, fornecedores, comunidade, Governo, clientes, entre outros). Os autores também reafirmam que o compromisso das empresas com o meio ambiente e o turismo sustentável se deu basicamente devido a duas principais pressões essenciais, quais sejam: a demanda do consumidor por um turismo mais socialmente e ambientalmente responsável preocupado com a preservação do atrativo turístico e a ameaça de regulação governamental, que impulsionou as empresas a adotarem uma postura eticamente responsável.

A partir destas considerações, pode-se inferir que o turismo é uma das atividades econômicas que tem o potencial de desenvolver regiões de maneira mais sustentável, porém é necessário refletir sobre os impactos ambientais, sociais, econômicos e culturais dessa atividade, no intuito de atender aos princípios da sustentabilidade.

\subsection{Sistema de Indicadores de Sustentabilidade do Desenvolvimento do Turismo}

Os sistemas de indicadores de sustentabilidade correspondem aos mecanismos que são adotados para avaliar o nível do desenvolvimento sustentável de um dado espaço territorial ou de uma dada atividade econômica. Para Van Bellen (2006), o objetivo principal dos indicadores é o de agregar e qualificar informações de maneira que sua significância fique mais aparente. Para o autor, os indicadores simplificam as informações sobre fenômenos complexos, melhorando o processo de comunicação e gestão.

Por sua vez, a definição de um sistema de indicadores, assim como a elaboração de instrumentos e técnicas para sua medição, tornou-se prioritária e um componente fundamental para os processos de planejamento e gestão de destinos turísticos, exigindo bases e aplicação práticas de modelos propostos (Hanai, 2009). Ante ao exposto, preocupado com a problemática ambiental, o rápido crescimento demográfico e a multiplicidade de atividades 
humanas que consomem e exploram os recursos naturais, Hanai (2009) propôs um Sistema de Indicadores de Sustentabilidade denominado: Sistema de Indicadores de Sustentabilidade do Desenvolvimento do Turismo (SISDTur).

A motivação principal para a criação do sistema foram às preocupações com os problemas e desafios socioeconômicos e ambientais, relacionados ao uso dos recursos hídricos e à estrita dependência econômica da produção agropecuária nesta região que despertaram no pesquisador, a necessidade e a proposição de oportunidades de desenvolvimento local, visando propiciar melhores condições de vida aos moradores locais por meio da criação e implementação de um conjunto de indicadores de desenvolvimento sustentável que verifiquem e avaliem a efetivação das condições de sustentabilidade (ambiental, social, econômica, cultural, turística e institucional) do desenvolvimento do turismo.

O processo de desenvolvimento da pesquisa envolveu: a contextualização do desenvolvimento sustentável e da sustentabilidade aplicada ao turismo; a análise das condições atuais do desenvolvimento turístico na região; a elaboração e a aplicação do programa de sensibilização turística; a abordagem conceitual e tipológica de indicadores, assim como as iniciativas, os sistemas e os modelos de indicadores do turismo sustentável, levantados e obtidos a partir de estudos de casos; o processo de seleção e definição de indicadores de sustentabilidade, por meio da abordagem participativa da sociedade local de Bueno Brandão, levando em consideração visões de outros grupos envolvidos na pesquisa (turismólogos e graduandos de Engenharia Ambiental); e a elaboração e proposição do SISDTur, configurando-o como um instrumento metodológico prático, útil e exequível para subsidiar o processo de desenvolvimento, gestão e monitoramento do turismo na região, consonante com os princípios de sustentabilidade (Hanai, 2009).

Nessa concepção, o SISDTur compreende dois conjuntos de indicadores: indicadores de sustentabilidade em estabelecimentos turísticos e espaços de visitação; e indicadores de sustentabilidade da gestão turística municipal, com descritores, indicadores, parâmetros, procedimentos técnicos, diretrizes e orientações para a identificação e obtenção de informações e dados sobre o turismo, distribuídos nas seis dimensões de sustentabilidade: ambiental, social, cultural, econômica, turística e institucional.

O sistema considera a necessidade prioritária de investigar cientificamente procedimentos e indicadores para a análise do processo de desenvolvimento do turismo, no sentido de propiciar a elaboração de instrumentos técnicos e científicos para a sua medição, auxiliando a tomada de decisões e a gestão sustentável da atividade turística. Assim como, a definição e o estabelecimento de indicadores que não somente avaliem os impactos da atividade econômica, mas também identifiquem as ações e as iniciativas que evitem os possíveis impactos negativos relacionados ao desenvolvimento do turismo numa dada localidade.

Por fim, complementando este cenário, Hanai (2009) ressalta a importância de novos estudos e pesquisas sobre indicadores de sustentabilidade na atividade turística e a necessidade de elaboração de instrumentos e procedimentos de análise da sustentabilidade e de 
monitoramento do turismo a fim de auxiliar o planejamento e a gestão de atividades turísticas nos espaços rurais, o que se buscou identificar e analisar na proposta da presente pesquisa.

\section{PROCEDIMENTOS METODOLÓGICOS}

A pesquisa pode ser classificada como exploratória e descritiva conduzida sob a forma de um estudo de caso. O levantamento dos dados foi realizado a partir da seleção de 41 indicadores, considerando características específicas do município pesquisado, assim como, as formas de funcionamento da atividade turística no contexto da pesquisa. Além disso, foi feita uma adaptação nos parâmetros específicos, forma de medição e dos tipos de unidade de medidas para adequar os indicadores à realidade do município e à base de dados disponível.

A partir dos indicadores selecionados foi elaborado um instrumento de pesquisa para coleta de dados primários, de forma complementarem, para o desenvolvimento da pesquisa foram realizadas visitas de reconhecimento ao município lócus do estudo, levantamento dos dados primários, dados secundários e informações necessárias para o delineamento do estudo sobre o município. Por fim, para atender ao problema de pesquisa e aos objetivos propostos no início do trabalho, foi levado em consideração para ambos os casos a triangulação: análise dos dados secundários, análise dos dados primários e inferências do pesquisador por meio da observação não participante.

Para o levantamento dos dados primários, foi aplicada a amostragem não probabilística por acessibilidade, dada a grande quantidade e heterogeneidade dos atores sociais direta e indiretamente envolvidos com atividade turística na região e a dificuldade no acesso a estes atores. Neste caso, a amostra foi representada por 48 atores sociais, envolvendo elementos da amostra composta por representantes da sociedade civil, iniciativa privada e poder público.

Após o levantamento bibliográfico sobre os diferentes modelos de indicadores utilizados para a atividade turística, e a compreensão do SISDTur, foi feita uma aplicação inicial do instrumento de pesquisa, levando em consideração o grau de discordância ou concordância a respeito das afirmativas feitas sobre os indicadores de sustentabilidade utilizados para atividade turística, uma vez que, as repostas deveriam se enquadrar na escala Likert. Nesta fase, os respondentes deveriam indicar seu grau de concordância ou discordância em relação à afirmativa marcando uma das cinco categorias de resposta. Definido o questionário e a compreensão de suas variáveis, foi realizada uma visita de reconhecimento da área de estudo, seguindo da aplicação dos questionários e da observação não participante, identificando os atores sociais que lidam com a atividade turística.

Assim, levando em consideração os dados secundários como auxílio, foram estabelecidos três estágios de critérios de análises dos dados: análise dos indicadores, análise da dimensão e análise global do nível de sustentabilidade da atividade turística do município. 
Para a análise dos indicadores das dimensões foi considerada a seguinte escala, utilizada por Barreto, Alves e Morais (2012), que sugere o seguinte:

\begin{tabular}{|c|c|}
\hline Média (escala de Likert) & Classificação \\
\hline $1,00-1,80$ & Discordância Total \\
\hline $1,90-2,60$ & Discordância Parcial \\
\hline $2,70-3,40$ & Neutralidade \\
\hline $3,50-4,20$ & Concordância Parcial \\
\hline $4,30-5,00$ & Concordância Total \\
\hline
\end{tabular}

Além disso, foi utilizado o Desvio-padrão (DP). No caso, as variáveis que representam DP até 2 indicam baixa dispersão, entre 2 e 3 moderada dispersão e DP acima de 3 alta dispersão dos dados (respostas) em relação à média.

Por sua vez, o Coeficiente de Variação (CV), buscou categorizar as respostas dos dados primários quanto à representatividade da média e quanto ao grau de dispersão, criando condições para saber se as repostas foram homogêneas ou heterogêneas. Para isso, utilizou-se como critério de análise a distribuição proposta por Oliveira (2010), em que:

- CV menor que 0,15\% significa baixa variabilidade das respostas em torno da média;

- CV maior ou igual a $0,15 \%$ ou menor ou igual a $0,30 \%$ significa moderada variabilidade das respostas em torno da média; e,

- CV maior que 0,30\% significa alta variabilidade das respostas em torno da média.

Esse critério foi satisfatório para análise dos indicadores, à medida que, após realização do cálculo, os resultados foram comparados com os dados secundários e pela observação não participante que confirmaram os resultados obtidos por esse critério.

No segundo estágio para saber se a dimensão encontra-se insustentável, parcialmente insustentável, em sustentabilidade intermediária, potencialmente sustentável ou sustentável, para cada dimensão, calculou-se a proporção do número de indicadores de sustentabilidade da dimensão pela soma das quantidades de indicadores sustentáveis da dimensão, para saber a relação percentual do nível de sustentabilidade da mesma. Dessa forma, obtém-se o seguinte critério de classificação: 


\begin{tabular}{|c|c|}
\hline Variação Percentual & Classificação \\
\hline $0-20 \%$ & Insustentável \\
\hline $21-40 \%$ & Parcialmente insustentável \\
\hline $41-60 \%$ & Sustentabilidade intermediária \\
\hline $61-80 \%$ & Potencialmente sustentável \\
\hline $81-100 \%$ & Sustentável \\
\hline
\end{tabular}

Por último, a análise global da sustentabilidade buscou mensurar qual o nível de sustentabilidade da atividade turística do município de Areia-PB, levando em consideração a soma do total de indicadores sustentáveis do conjunto de dimensões. Para isso, foram estabelecidas 5 faixas que enquadram o nível de desenvolvimento sustentável constatado na atividade turística praticada pelo município, conforme quadro abaixo:

\begin{tabular}{|c|c|}
\hline $\begin{array}{c}\text { Quantidade de indicadores sustentá- } \\
\text { veis }\end{array}$ & Classificação \\
\hline $0-10$ & Insustentável \\
\hline $11-20$ & Pustentabilidade intermediária \\
\hline $21-30$ & Potencialmente sustentável \\
\hline $31-40$ & Sustentável \\
\hline Acima de 40 & \\
\hline
\end{tabular}

O período de coleta de dados foi de outubro de 2014 a abril de 2015, sendo realizadas várias visitas de campo. Do ponto de vista da ética na pesquisa, informa-se que os respondentes: atores da sociedade civil, iniciativa privada e poder público, foram informados de sua condição voluntária em responder aos questionários. Desse modo, como forma de resguardar esses atores, não serão divulgados seus nomes sendo a sua identidade preservada.

\section{APRESENTAÇÃO E ANÁLISE DOS RESULTADOS}

\subsection{Caracterização do lócus da pesquisa: Areia - PB}


O município de Areia está localizado na microrregião do brejo paraibano, atualmente a sua população de 23.829 habitantes, com estimação populacional de 23.110 no ano de 2015, conforme dados do Instituto Brasileiro de Geografia e Estatística (IBGE, 2010). A área territorial do município corresponde a $266,596 \mathrm{~km}^{2}$ com densidade demográfica de $88,42 \mathrm{hab} / \mathrm{km}^{2}$, com temperatura média anual oscilando em torno dos 23,5ㅇ C (FAMUP, 2013).

Com investimentos para o desenvolvimento local, agropecuária, indústria, serviços e as contribuições da atividade turística, o município apresenta um Índice de Desenvolvimento Humano Municipal (IDHM) médio no valor de 0,594, perfazendo um PIB per capita a preços correntes de $\mathrm{R} \$$ 7.047,08 reais (IBGE, 2016). O município de Areia, também denominado “Civilização do Açúcar", está situado na região do brejo paraibano, sendo conhecido nacionalmente e internacionalmente por sua produção de aguardente (cachaça), açúcar e rapadura (Areia, 2015).

No que se refere à atividade turística, a mesma teve um incremento após sua inclusão nos roteiros turísticos do brejo paraibano, o turismo ecológico, rural e cultural caracterizado pelo rico patrimônio histórico e cultural composto por igrejas, solares, teatros, engenhos, sobrados, museus, casarões e casas de farinha, por sua vez, o cultivo da cana de açúcar possibilitou a implantação de numerosos engenhos, onde se transformava essa matéria prima em produtos como o açúcar comum, o açúcar mascavo, a rapadura e a aguardente. Sendo, estes produtos, comercializados em função da demanda existente no litoral e no sertão do estado, com atual destaque para exportação de produtos artesãos e alimentícios para o exterior (Areia, 2015).

As casas e engenhos abertos à visitação construídos no século XX possuem características dos imóveis do século anterior, com móveis ornamentando os cômodos cuidadosamente dispostos, dando-lhe um ar rústico e histórico. As belezas culturais de Areia-PB contam também com o diversificado artesanato, grupos de tradições folclóricas e as comidas típicas regionais. Areia-PB também dispõe de guias turísticos, oficinas de artesanato, feirinha de produtos orgânicos, hotéis, pousadas, sítios, restaurantes regionais, bares, lanchonetes, cafés, sorveterias, pizzarias e cachaçarias. Além disso, outros eventos são realizados como atrativos para o fomento da atividade turística.

\subsection{Análise das Dimensões do SISDTur}

\subsubsection{Dimensão Ambiental}

A Tabela 01 abaixo apresenta a análise dos quatorzes indicadores que compõem esta dimensão, levando em consideração os dados primários, secundários e inferências do pesquisador por meio da observação não participante. 
Tabela 01 - Dados da Dimensão Ambiental

\begin{tabular}{|c|c|c|c|}
\hline Indicadores & Média & $\begin{array}{l}\text { Desvio- } \\
\text { padrão }\end{array}$ & CV (\%) \\
\hline $\begin{array}{l}\text { 1) A quantidade de água consumida por turista em um pe- } \\
\text { ríodo não afeta o consumo local. }\end{array}$ & 2,69 & 1,54 & 57,25 \\
\hline $\begin{array}{l}\text { 2) Existem programas de redução do consumo, desperdício } \\
\text { ou reuso de água. }\end{array}$ & 2,52 & 1,61 & 63,89 \\
\hline 3) Existe monitoramento da qualidade da água. & 2,48 & 1,59 & 64,11 \\
\hline $\begin{array}{l}\text { 4) A quantidade de resíduos sólidos gerados pela atividade } \\
\text { turística é em grande proporção. }\end{array}$ & 2,90 & 1,34 & 46,21 \\
\hline $\begin{array}{l}\text { 5) Existem programas de redução da quantidade de resí- } \\
\text { duos sólidos. }\end{array}$ & 2,69 & 1,40 & 52,04 \\
\hline $\begin{array}{l}\text { 6) Existe coleta seletiva de resíduos sólidos e processo de } \\
\text { reciclagem. }\end{array}$ & 2,65 & 1,53 & 57,74 \\
\hline $\begin{array}{l}\text { 7) A energia consumida por um turista em um período não } \\
\text { afeta o consumo da produção local e não é em grande pro- } \\
\text { porção. }\end{array}$ & 3,17 & 1,60 & 50,47 \\
\hline 8) Existem programas de redução do consumo de energia. & & 1,62 & 62,31 \\
\hline 9) Existe processo de tratamento de esgotos. & 3,02 & 1,64 & 54,30 \\
\hline $\begin{array}{l}\text { 10) Existem áreas preservadas, recuperadas ou em pro- } \\
\text { cesso de recuperação. }\end{array}$ & 3,63 & 1,41 & 38,84 \\
\hline $\begin{array}{l}\text { 11) Existem programas ou instalações para melhoria da } \\
\text { qualidade do ar. }\end{array}$ & 1,83 & 1,11 & 60,66 \\
\hline $\begin{array}{l}\text { 12) Existe programa orientado de interpretação em educa- } \\
\text { ção ambiental ou cultural. }\end{array}$ & 3,42 & 1,32 & 38,60 \\
\hline $\begin{array}{l}\text { 13) Existem associações de grupos ambientalistas na loca- } \\
\text { lidade. }\end{array}$ & 3,35 & 1,31 & 39,10 \\
\hline 14) Existe processo de certificação ambiental ou turística. & 3,33 & 1,31 & 39,34 \\
\hline
\end{tabular}

Fonte: Dados da pesquisa (2015)

Diante do exposto, infere-se dos dados obtidos que a dimensão ambiental do desenvolvimento do turismo sustentável do município de Areia-PB apresentou do total de quatorze indicadores: cinco indicadores sustentáveis; um indicador parcialmente sustentável; dois indicadores em sustentabilidade intermediária; quatro indicadores parcialmente insustentáveis.

Nesse sentido, constata-se que a dimensão ambiental do município de Areia-PB encontra-se parcialmente insustentável, tendo em vista que, o total da Média dos indicadores indicam que aproximadamente $60 \%$ das respostas correspondem a discordância total e discordância parcial e $40 \%$ corresponde a neutralidade (nem concordo, nem discordo) e concordância parcial das respostas em relação à afirmativa, com baixo desvio-padrão e alta variabilidade das repostas em torno da média para todos os indicadores, carecendo de seus gestores público municipais melhores investimentos na estrutura e infraestrutura do saneamento básico da cidade, como a implementação de instalações de abastecimento e tratamento da 
água; e, gestão, tratamento e destinação segura dos esgotos sanitários e dos resíduos sólidos gerados pelos moradores do município e pela atividade turística, visando preservar os corpos hídricos e as matas do entorno da cidade, de modo que não comprometam a higiene e a qualidade de vida de seus moradores, da vida silvestre e dos visitantes como um todo.

Por sua vez, de acordo com a gestão municipal de saneamento básico, o município de Areia-PB faz parte do número de municípios paraibanos que não possuem programas de redução e manejo seguro da quantidade de resíduos sólidos gerados, por isso, este indicador apresenta-se insustentável. Mucelin e Bellini (2008) frisam que em nenhuma outra etapa do desenvolvimento humano, como a atual, gerou-se tanto resíduo (lixo) e prejudicou-se tanto a saúde das populações humanas e o próprio meio ambiente.

Assim, o indicador: existência de programas de redução da quantidade de resíduos sólidos, bem como de gestão (coleta, acondicionamento, disposição), merecem atenção especial dos gestores municipais no desenvolvimento de programas de conscientização para minimização de resíduos sólidos, de forma que promovam políticas públicas voltadas ao saneamento básico e manejo de resíduos sólidos, para disposição segura dos resíduos em aterros sanitários ou incineradores, de forma que não comprometam a qualidade ambiental.

Por fim, a observação não participante "in loco" permitiu constatar que o poder público municipal deve intervir e criar ações mitigadoras no sentido de promover investimentos, políticas públicas e programas que possam minimizar os impactos negativos do turismo no meio ambiente. Para isso, os sistemas de indicadores de desenvolvimento sustentável do turismo podem nortear a elaboração de planos, projetos e políticas públicas no sentido de preservar, conservar e restaurar o patrimônio histórico, turístico, cultural e os recursos naturais do município e região.

\subsubsection{Dimensão Cultural}

A Tabela 02 apresenta a análise dos sete indicadores inerentes a esta dimensão, levando em consideração os dados primários, dados secundários e inferências do pesquisador por meio da observação não participante. 
Tabela 02 - Dados da Dimensão Cultural

\begin{tabular}{l|c|c|c}
\hline Indicadores & Média & $\begin{array}{c}\text { Desvio- } \\
\text { padrão }\end{array}$ & CV (\%) \\
\hline $\begin{array}{l}\text { 1) Existe uma boa quantidade de produtos típi- } \\
\text { cos locais ofertados (artesanato, souvenirs, etc.). }\end{array}$ & 4,48 & 1,06 & 23,66 \\
$\begin{array}{l}\text { 2) Existe uma boa quantidade de bens patrimo- } \\
\text { niais, arquitetônicos, arqueológicos e históricos. }\end{array}$ & 4,38 & 0,97 & 22,15 \\
$\begin{array}{l}\text { 3) Existe uma boa quantidade de eventos e festi- } \\
\text { vidades populares tradicionais de manifestações } \\
\text { culturais. }\end{array}$ & 3,60 & 1,35 & 37,50 \\
$\begin{array}{l}\text { 4) Existem atos de vandalismo praticados por tu- } \\
\text { ristas aos artefatos culturais. }\end{array}$ & 2,23 & 1,37 & 61,43 \\
$\begin{array}{l}\text { 5) Existem atos de vandalismo praticados por re- } \\
\text { sidentes aos artefatos culturais. } \\
\text { 6) Houve mudança no modo de vestir e interesse }\end{array}$ & 3,08 & 1,46 & 47,40 \\
$\begin{array}{l}\text { por aprender novas línguas. } \\
\text { 7) Houve mudança na percepção sobre dificulda- } \\
\text { des de estacionamento nas ruas principais. }\end{array}$ & 3,46 & 1,63 & 39,25 \\
\hline
\end{tabular}

Fonte: Dados da pesquisa (2015)

De acordo com a pesquisa, os resultados indicam que a dimensão cultural do município de Areia-PB apresentou do total de sete indicadores, três indicadores sustentáveis; um indicador parcialmente sustentável; dois indicadores parcialmente insustentáveis.

Portanto, conforme foi apresentada, a dimensão cultural do desenvolvimento do turismo sustentável do município de Areia-PB encontra-se em sustentabilidade intermediária, haja vista que, o total da Média dos indicadores indicam que aproximadamente $60 \%$ das respostas correspondem a neutralidade (nem concordo, nem discordo) e $40 \%$ corresponde a concordância parcial e concordância total das respostas em relação a afirmativa, com baixo desvio-padrão e de moderada à alta variabilidade das repostas em torno da média para todos os indicadores.

Dessa feita, é importante considerar que a dimensão está caminhando para um desenvolvimento turístico mais sustentável, contudo, está necessitando de mais investimentos em infraestrutura e estabelecimento de planos, projetos, políticas e estratégias voltados ao desenvolvimento de um turismo mais sustentável e responsável em termos ambientais e culturais.

Para isso, o poder público, a iniciativa privada e a sociedade civil em comum acordo podem estar implementando um instrumento de análise que mensure o desenvolvimento de um turismo mais sustentável, utilizando como ferramenta um sistema de indicadores de sustentabilidade que auxilie e oriente o gestor no processo de desenvolvimento do turismo sustentável, pois além de serem de fácil entendimento, são capazes de fomentar a comunicação na sociedade e fornecer informações adequadas para a tomada de decisão. 


\subsubsection{Dimensão Social}

A Tabela 03 apresenta a análise dos cinco indicadores que formam esta dimensão, levando em consideração os dados primários, dados secundários e inferências do pesquisador por meio da observação não participante.

Tabela 03 - Dados da Dimensão Social

\begin{tabular}{l|c|c|c}
\hline Indicadores & Média & $\begin{array}{c}\text { Desvio- } \\
\text { padrão }\end{array}$ & CV (\%) \\
\hline $\begin{array}{l}\text { 1) Existe um bom número de residentes lo- } \\
\text { cais empregados nos estabelecimentos turís- } \\
\text { ticos. }\end{array}$ & 3,02 & 1,57 & 51,99 \\
$\begin{array}{l}\text { 2) Existem iniciativas de capacitação e treina- } \\
\text { mento profissional aos funcionários residen- } \\
\text { tes locais. }\end{array}$ & 3,27 & 1,44 & 44,04 \\
$\begin{array}{l}\text { 3) Existem funcionários residentes locais com } \\
\text { capacitação em turismo. }\end{array}$ & 3,63 & 1,20 & 33,06 \\
$\begin{array}{l}\text { 4) Os empregos fixos no setor turístico são } \\
\text { mais que os empregos temporários. }\end{array}$ & 2,75 & 1,46 & 53,09 \\
$\begin{array}{l}\text { 5) Existe satisfação da população local com o } \\
\text { turismo. }\end{array}$ & 3,65 & 1,35 & 36,99 \\
\hline
\end{tabular}

Fonte: Dados da pesquisa (2015)

A partir da análise dos respectivos indicadores que englobam a dimensão social, verifica-se que o município de Areia-PB apresentou do total de cinco indicadores, dois indicadores sustentáveis; dois indicadores parcialmente insustentáveis e um indicador parcialmente sustentável. A média dos indicadores indicam que aproximadamente $80 \%$ das respostas correspondem a neutralidade (nem concordo, nem discordo) e $20 \%$ corresponde a discordância parcial das respostas em relação a afirmativa, com baixo desvio-padrão e alta variabilidade das repostas em torno da média para todos os indicadores.

Diante dessa análise, a dimensão social do desenvolvimento do turismo sustentável do município de Areia-PB classifica-se como parcialmente insustentável, haja vista que, à visita a escolas técnicas profissionalizantes evidenciou que a gestão municipal desenvolve iniciativas, como cursos técnicos voltados à qualificação profissional, contribuindo para a população local ter acesso ao mercado de trabalho, como também, para o desenvolvimento das atividades turísticas com qualidade.

Todavia, esta dimensão merece melhor atenção dos gestores municipais quanto à formulação de políticas públicas voltadas para a atividade turística. Sendo de suma importância que a sustentabilidade social busque oferecer e garantir as prerrogativas básicas asseguradas pela Constituição Federal Brasileira de serviços básicos como educação, saúde, segurança, 
transporte e emprego, para que, por meio deles se alcance o almejado desenvolvimento de um turismo mais sustentável e de acesso igualitário.

\subsubsection{Dimensão Econômica}

A Tabela 04 apresenta a análise dos cinco indicadores que compõem esta dimensão, levando em consideração os dados primários, dados secundários e inferências do pesquisador por meio da observação não participante.

Tabela 04 - Dados da Dimensão Econômica

\begin{tabular}{l|c|c|c}
\hline Indicadores & Média & $\begin{array}{c}\text { Desvio- } \\
\text { padrão }\end{array}$ & CV (\%) \\
\hline $\begin{array}{l}\text { 1) A atividade turística gera renda e emprego } \\
\text { para a população local. }\end{array}$ & 4,15 & 1,27 & 30,60 \\
$\begin{array}{l}\text { 2) Os estabelecimentos turísticos se mantem há } \\
\text { um bom tempo de permanência no destino turís- }\end{array}$ & 3,58 & 1,20 & 33,52 \\
$\begin{array}{l}\text { tico. } \\
\text { 3) Os estabelecimentos turísticos funcionam nos } \\
\text { finais de semana e feriados. }\end{array}$ & 3,67 & 1,39 & 37,87 \\
$\begin{array}{l}\text { 4) Os turistas gastam uma boa quantidade de re- } \\
\text { cursos financeiros por dia nos estabelecimentos } \\
\text { turísticos. }\end{array}$ & 3,90 & 1,12 & 28,72 \\
$\begin{array}{l}\text { 5) Os investimentos anuais em turismo são equi- } \\
\text { librados e atendem ao aumento da demanda. }\end{array}$ & 3,06 & 1,30 & 42,48 \\
\hline
\end{tabular}

Fonte: Dados da pesquisa (2015)

A dimensão econômica dos indicadores de desenvolvimento sustentável avalia o desempenho macro e micro econômico-financeiro e os impactos dos investimentos em infraestrutura dos atrativos turísticos.

Nesse sentido, a dimensão econômica do desenvolvimento do turismo sustentável do município de Areia-PB apresentou do total de cinco indicadores, um indicador sustentável; um indicador parcialmente sustentável; um indicador em sustentabilidade intermediária e dois indicadores parcialmente insustentáveis.

Não obstante, os resultados obtidos permitem afirmar que a dimensão econômica do município de Areia-PB encontra-se insustentável, ao passo que, o total da média dos indicadores indica que aproximadamente $80 \%$ das respostas correspondem a neutralidade (nem concordo, nem discordo) e $20 \%$ corresponde a concordância parcial das respostas em relação a afirmativa, com baixo desvio-padrão e de moderada à alta variabilidade das repostas em torno da média para todos os indicadores.

A triangulação dos dados e a observação não participante "in loco" evidenciam que o planejamento do turismo ainda é incipiente frente à demanda turística que o município vem 
sofrendo, carecendo de seus gestores públicos municipais melhores investimentos na estrutura e infraestrutura urbana da cidade como um todo, ao passo que, o acesso à vias e ruas da cidade e o percurso até os engenhos requerem melhores condições de infraestrutura, iluminação, sinalização, saneamento, segurança, entre outros.

\subsubsection{Dimensão Turística}

A Tabela 05 apresenta a análise dos onze indicadores inerentes a esta dimensão, levando em consideração os dados primários, dados secundários e inferências do pesquisador por meio da observação não participante.

Tabela 05 - Dados da Dimensão Turística

\begin{tabular}{|c|c|c|c|}
\hline Indicadores & Média & $\begin{array}{l}\text { Desvio- } \\
\text { padrão }\end{array}$ & CV (\%) \\
\hline $\begin{array}{l}\text { 1) A oferta de hospedagem é suficiente para atender à } \\
\text { demanda Turística. }\end{array}$ & 3,08 & 1,51 & 49,03 \\
\hline $\begin{array}{l}\text { 2) Existem facilidades para mobilidade de pessoas com } \\
\text { dificuldades de locomoção ou outras necessidades es- } \\
\text { peciais. }\end{array}$ & 2,13 & 1,35 & 63,38 \\
\hline 3) Existe registro de controle da visitação. & 3,67 & 1,31 & 35,69 \\
\hline $\begin{array}{l}\text { 4) Existe programação de atividades educacionais e visi- } \\
\text { tas guiadas a atrações de interesse ambiental ou cultu- } \\
\text { ral. }\end{array}$ & 3,46 & 1,24 & 35,84 \\
\hline $\begin{array}{l}\text { 5) Existe proporção do tempo gasto pelo turista em visi- } \\
\text { tações ou atrações de interesse ambiental ou cultural. }\end{array}$ & 3,04 & 1,04 & 34,21 \\
\hline $\begin{array}{l}\text { 6) Os empreendimentos turísticos e os turistas respei- } \\
\text { tam a capacidade de carga dos atrativos. }\end{array}$ & 3,35 & 1,18 & 35,22 \\
\hline 7) Existe equilíbrio entre o número de guias e turistas. & 3,02 & 1,44 & 47,68 \\
\hline $\begin{array}{l}\text { 8) Existem muitos incidentes e acidentes envolvendo } \\
\text { turistas ou visitantes. }\end{array}$ & 1,71 & 1,08 & 63,16 \\
\hline $\begin{array}{l}\text { 9) Os turistas ficam satisfeitos com os serviços ofereci- } \\
\text { dos e voltam outras vezes ao município. }\end{array}$ & 4,02 & 1,11 & 27,61 \\
\hline $\begin{array}{l}\text { 10) Existem taxas de visitação pagas para contribuições } \\
\text { de proteção, conservação ou utilização dos atrativos tu- } \\
\text { rísticos. }\end{array}$ & 2,42 & 1,35 & 55,79 \\
\hline $\begin{array}{l}\text { 11) Existem instalações e estruturas de minimização } \\
\text { dos impactos ambientais decorrentes do turismo. }\end{array}$ & 2,40 & 1,27 & 52,92 \\
\hline
\end{tabular}
Fonte: Dados da pesquisa (2015)

Para acompanhar a demanda de um turismo crescente que vem se desenvolvendo nos âmbitos internacionais, estaduais e municipais, a exemplo do município de Areia-PB, políticas públicas, projetos e programas devem ser elaborados e estar comprometidos com os princípios do desenvolvimento sustentável para que as futuras gerações também possam desfrutar e conhecer essas áreas de história, lazer, cultura e informação. 
Dentro dessa linha de argumentação, constata-se que a dimensão turística do desenvolvimento do turismo sustentável do município de Areia-PB, localizado na microrregião do brejo paraibano apresentou do total de onze indicadores, dois indicadores sustentáveis; um indicador parcialmente sustentável; um indicador em sustentabilidade intermediária; quatro indicadores parcialmente insustentáveis e três indicadores insustentáveis.

A média dos indicadores indica que aproximadamente $65 \%$ das respostas correspondem a neutralidade (nem concordo, nem discordo) e 35\% corresponde a discordância parcial, discordância total e concordância parcial das respostas em relação à afirmativa, com baixo desvio-padrão e de moderada à alta variabilidade das repostas em torno da média para todos os indicadores.

Constatou-se por meio da observação não participante "in loco" que, no tange aos mecanismos de registro e controle de visitação, as visitas em museus, igrejas, sobrados, teatros e engenhos, são deficitários e requerem segurança, controle e fiscalização para que haja controle da capacidade de carga dos atrativos, de forma que não haja degradação, depreciação ou violação dos bens que formam o produto turístico. Desse modo, a fiscalização e o controle devem ser praticados de maneira mais intensiva visando salvaguardar os bens naturais e patrimoniais para as futuras gerações conforme os princípios da sustentabilidade.

Nesse sentido, os resultados obtidos permitem concluir que a dimensão turística do município de Areia-PB apresenta-se insustentável, carecendo da administração pública municipal incrementar os investimentos na estrutura e infraestrutura da atividade turística como um todo. Esta dimensão também merece melhor atenção dos gestores locais na formulação de ações, políticas públicas, programas, projetos e investimentos que viabilizem o desenvolvimento sustentável do turismo, uma vez que, a zona urbana e rural do município de Areia-PB evidencia o grande potencial turístico que a cidade pode oferecer em termos de turismo de aventura, rural, ecológico, cultural, eventos e gastronômico cabendo aos atores sociais da sociedade civil, da iniciativa privada e do poder público enaltecer os valiosos bens naturais e patrimoniais que formam o produto turístico no município.

\subsubsection{Dimensão Institucional}

A Tabela 06 apresenta a análise dos cinco indicadores que formam esta dimensão, levando em consideração os dados primários, dados secundários e inferências do pesquisador por meio da observação não participante. 
Tabela 06 - Dados da Dimensão Institucional

\begin{tabular}{l|c|c|c}
\hline Indicadores & $\begin{array}{c}\text { Mé- } \\
\text { dia }\end{array}$ & $\begin{array}{c}\text { Desvio- } \\
\text { padrão }\end{array}$ & CV (\%) \\
\hline $\begin{array}{l}\text { 1) A Capacitação e o apoio Técnico em Turismo } \\
\text { é suficiente para atender à demanda Turística. }\end{array}$ & 2,88 & 1,38 & 47,92 \\
$\begin{array}{l}\text { 2) Existe participação da comunidade local na } \\
\text { elaboração e gestão de planos para o turismo }\end{array}$ & 3,21 & 1,38 & 42,99 \\
local. & & 1,32 & 37,29 \\
$\begin{array}{l}\text { 3) Existem estratégias de promoção e comerci- } \\
\text { alização dos produtos turísticos. }\end{array}$ & 3,54 & 1,12 & 25,87 \\
$\begin{array}{l}\text { 4) Existe legislação para a proteção do patrimô- } \\
\text { nio histórico na localidade. }\end{array}$ & 4,33 & 1,11 & 27,21 \\
$\begin{array}{l}\text { 5) Existe legislação para a proteção do patrimô- } \\
\text { nio natural na localidade. }\end{array}$ & 4,08 & 1,10 \\
\hline
\end{tabular}

Fonte: Dados da pesquisa (2015)

A partir dos resultados obtidos, verificou-se que a dimensão institucional do desenvolvimento do turismo sustentável do município de Areia-PB apresentou do total de cinco indicadores, três indicadores sustentáveis; um indicador parcialmente insustentável e um indicador insustentável.

Neste sentido, pode-se inferir que a dimensão institucional de Areia-PB encontra-se em sustentabilidade intermediária, pois o total da média dos indicadores indica que aproximadamente $60 \%$ das respostas correspondem discordância parcial e neutralidade (nem concordo, nem discordo) e $40 \%$ corresponde a concordância parcial das respostas em relação a afirmativa, com baixo desvio-padrão e de moderada à alta variabilidade das repostas em torno da média para todos os indicadores.

Cabe destacar que a dimensão institucional está caminhando para um desenvolvimento turístico mais sustentável, haja vista que, por meio do Instituto do Patrimônio Histórico e Artístico Nacional (IPHAN), o órgão nacional vinculado ao Ministério da Cultura (MinC), responsável por promover e coordenar o processo de preservação e valorização do Patrimônio Cultural Brasileiro, em suas dimensões material e imaterial, dispõe de uma superintendência no Estado da Paraíba, o Instituto do Patrimônio Histórico e Artístico Nacional do Estado da Paraíba (IPHANEP), que é o órgão responsável pela melhoria dos serviços do setor, tombamento, fiscalização, conservação, aumento de visitação e arrecadação dos museus, fomento de políticas de aquisição e preservação dos acervos, revelando que o município já dispõe de dispositivos físicos e legais que garantem a preservação, conservação, restauração, controle e fiscalização de seus artefatos históricos, culturais, naturais e turísticos.

Para minimizar os problemas acima identificados, a gestão municipal deve fomentar e promover políticas públicas de capacitação e apoio técnico em turismo, de forma que, por 
meio deles, também conscientizem, sensibilizem e promovam a importância que se tem em preservar e divulgar sua história, seu patrimônio, sua cultura, seu turismo, pois mais que uma fonte de renda, lazer e cultura, é antes de tudo, seu patrimônio. Outro aspecto que devem levar em consideração é a organização de reuniões participativas para ouvir a opinião e/ou sugestão dos moradores para fazerem uma gestão mais integrada e participativa da população.

\section{CONCLUSÕES}

A aplicação do SISDTur permitiu identificar o nível de sustentabilidade da atividade turística do município de Areia-PB e ao mesmo tempo forneceu um conjunto de informações fundamentais para a formulação e implementação de ações, investimentos, projetos e políticas públicas voltados ao desenvolvimento do turismo sustentável.

A análise do desenvolvimento sustentável da atividade turística de Areia-PB revelou através da triangulação dos dados e da observação não participante "in loco" que as atividades turísticas do município encontram-se em sustentabilidade intermediária, comprovada pela análise global da sustentabilidade, pois do total de 47 (quarenta e sete) indicadores de sustentabilidade o município apresentou (16) dezesseis indicadores sustentáveis, 05 (cinco) parcialmente sustentáveis, (04) quatro em sustentabilidade intermediária, 15 (quinze) parcialmente insustentáveis e (07) sete indicadores insustentáveis, perfazendo um total de 25 (vinte e cinco) indicadores com sustentabilidade média ou alta e vinte e dois restantes podendo ser considerados como de baixa sustentabilidade.

Posto isto, considerando a análise das dimensões e os parâmetros estabelecidos pela metodologia utilizada, a síntese da análise do desenvolvimento sustentável da atividade turística de Areia-PB, permite concluir que das seis dimensões analisadas e apresentadas pela metodologia SISDTur, 02 (duas) apresentaram-se em sustentabilidade intermediária: Cultural e Institucional; (02) duas parcialmente insustentáveis: Ambiental e Social; e 02 (duas) insustentáveis: Econômica e Turística. Neste caso, tem-se quatro dimensões que apresentam resultados desfavoráveis à sustentabilidade da atividade turística no município pesquisado.

Nesse sentido, estas dimensões merecem melhor atenção dos gestores públicos municipais na implementação de ações, investimentos, planos e projetos de desenvolvimento sustentável do turismo para que possam viabilizar melhorar e contribuir com o desenvolvimento do turismo no município, haja vista que, o turismo é uma atividade que está em grande expansão, sobretudo no Brasil, devendo, por isso, ser planejado a partir dos princípios de sustentabilidade.

Os resultados obtidos com a realização da pesquisa coincide com o argumento de Leff (2002), quando afirma que é preciso estudar os efeitos da problemática ambiental sobre as transformações metodológicas, as transferências conceituais e a circulação terminológica entre as diferentes disciplinas que participam na explicação e diagnóstico das transformações 
socioambientais. Outros estudos realizados por Reyna (2002), Arranda, (2003), Cintra (2004), Lacerda (2011), Santos (2013), e Silva, (2015) confirmam os resultados encontrados nesta pesquisa, que encontram baixos níveis de sustentabilidade em diversos destinos turísticos, tendo como causa principal a ausência ou inadequação de práticas de gestão e planejamento adequado das atividades turísticas e dos recursos ambientais e naturais.

\section{REFERÊNCIAS}

Areia - Prefeitura Municipal de Areia-PB. (2015). História. Acedido em janeiro, 23 de 2015, em http://www.areia.pb.gov.br/historia/.

. (2015). Pontos turísticos: curiosidades turísticas. Acedido em janeiro, 23 de 2015, em http://www.areia.pb.gov.br/turismo/pontos-turisticos-2/.

Arranda, T. X. (2003). Un sistema de indicadores sostenibles aptos para um destino turístico: un fundamento metodológico. In: Simpósio Internacional de Turismo Y Ocio. Barcelona, Espanha. Barcelona (Espãna): ESADE, Fira Barcelon.

Barreto, M. T., Alves, M. B., \& Morais, G. L. F. V. de. (2012). A Acessibilidade nas Empresas: Percepção dos Portadores de Deficiência Visual Inseridos no Mercado de Trabalho. Acedido em fevereiro, 04 de 2015, em http://gpi.aedb.br/seget/artigos12/28516237.pdf.

Beni, M. C. (2002). Análise estrutural do turismo. São Paulo: Editora SENAC.

Braga, D. C. (2007). Planejamento turístico: teoria e prática. Rio de Janeiro: Elsevier.

Brundtland - Report. (1987). Word Comission on Environment and Development: our common future. Oxford and New York.

Cintra, H. B. (2004). Indicador de sustentabilidade para o ecoturismo e o turismo rural. In: Anais... CONGRESSO ACADEMICO SOBRE MEIO AMBIENTE E DESENVOLVIMENTO DO RIO DE JANEIRO. Rio de Janeiro, anais.

Falcão, M. C., \& Gómez, C. R. P. (2010). Avaliando a sustentabilidade de um destino turístico: o caso de Fernando de Noronha. In: Candido, G. A. (Org.). Desenvolvimento Sustentável e Sistemas de Indicadores de Sustentabilidade: Formas de Aplicação em Contextos Geográficos Diversos e Contingências Específicas. Campina Grande-PB: UFCG.

FAMUP - Federação das Associações de Municípios da Paraíba. (2013). Portal dos Municípios da Paraíba. Acedido em janeiro, 25 de 2015, em http://www.famup.com.br/portal/index.php\#.

Gomes, B. M. A. (2009). Políticas Públicas e as Transações em Regiões Turísticas. (1. Ed). São Paulo: All Print.

Hanai, F. Y. (2009). Sistema de Indicadores de Sustentabilidade: Uma aplicação ao Contexto de Desenvolvimento do Turismo na Região de Bueno Brandão Estado de Minas Gerais, Brasil. Tese (Doutorado) - Universidade Federal de São Carlos - Escola de Engenharia de São Carlos, São Paulo. 
IBGE - Instituto Brasileiro de Geografia e Estatística. (2010). Paraíba - Areia. Acedido em janeiro, 25 de 2015, em http://cidades.ibge.gov.br/xtras/perfil.php?lang=\&codmun=250110\&search=paraiba|areia.

. (2016). Paraíba - Areia - síntese das informações. Acedido em janeiro, 25 de 2015, em http://cidades.ibge.gov.br/xtras/temas. php?lang=\&codmun=250110\&idtema=16\&search=paraiba|areia|sintese-das-informacoes.

Lacerda, C. de S. (2011). SISTEMA DE INDICADORES DE SUSTENTABILIDADE PARA ATIVIDADE TURISTICA: Uma proposta metodológica participativa aplicada no município do Conde/PB. Dissertação (Mestrado) - Programa de Pós-Graduação em Recursos Naturais - Universidade Federal de Campina Grande, Campina Grande.

Leff, E. (2002). Epistemologia ambiental. Tradução de Sandra Valenzuela. (2. Ed.). São Paulo: Cortez.

Ministério do Turismo. (2007). Estudos da competitividade do turismo brasileiro: turismo e a dimensão ambiental. Acedido em novembro, 20 de 2014, em http://www.turismo.gov.br/export/sites/\%20default/turismo/o ministerio/publicacoes/downloads publicacoes/O COMxRCIO INTERNACIONAL DE SERVIXOS OPERADORAS DE TURISM.

. (2014). Economia do turismo cresce no Brasil. Acedido em março, 08 de 2015, em http://www.turismo.gov.br/turismo/noticias/todas noticias/20140417-1.html.

Molina, S. (2011). Turismo e Ecologia. (1. ed). Bauru: Edusc.

Mucelin, C. A. \& Bellini, M. (2008). Garbage and perceptible environmental impacts in urban ecosystem. Society and Nature. (Online), v.20, n.1, pp. 213-232.

Oliveira, J. U. C. de. (2010). Estatística - Uma Nova Abordagem. (1. ed). Rio de Janeiro: Ciência Moderna Ltda.

OMT - ORGANIZAÇÃO MUNDIAL DE TURISMO. (2003). Guia de desenvolvimento do turismo sustentável. Tradução de Sandra Netz. Porto Alegre: Bookman.

Reyna, M. (2002). Propuesta de indicadores de turismo sostenible para Tenerife. In: Seminário Internacional Indicadores Ambientales De Turismo, 2002, Murcia (España). Informe... Murcia (España): Mullor y Asociados, p.62-72.

Rodrigues, A. B. (1999). Turismo: desenvolvimento local. São Paulo: Hucitec.

Santos, J. G., \& Cândido, G. A. (2013). Engajamento entre os atores sociais para o alcance do turismo sustentável: um estudo em Porto de Galinhas, PE. In: Perna, F., \& et al. (Orgs.). Economia, ambiente e sustentabilidade no turismo. Faro/Portugal: UAlg ESGHT.

. (2015). Geração e manejo dos resíduos sólidos resultantes das atividades turísticas de Porto de Galinhas - PE. Revista Brasileira de Pesquisa em Turismo. 9(1), 40-48. 
Silva, N. C. (2015). Sistema de indicadores de sustentabilidade do desenvolvimento do turismo: um estudo de caso do município de Areia - PB. Monografia (Graduação) - Universidade Federal de Campina Grande, Campina Grande.

Silva, W. A. C., \& et al. (2013). Infraestrutura brasileira de apoio turístico: avaliação da adequabilidade dos serviços públicos prestados na rodovia Fernão Dias. In: Perna, F., \& et al. (Orgs.). Economia, ambiente e sustentabilidade no turismo. Faro/Portugal: UAlg ESGHT.

Souza, M. J. de P., \& Ferreira, E. (2011). Planos Nacionais de Turismo, Desenvolvimento Local e Sustentabilidade. Acedido em fevereiro, 08 de 2015, em http://www.anpad.org.br/admin/pdf/ESO2544.pdf.

Van Bellen, H. M. (2006). Indicadores de sustentabilidade: uma análise comparativa. Rio de Janeiro: Fundação Getúlio Vargas.

Virginio, D. F., \& Fernandes, L. V. (2011). Responsabilidade socioambiental na hotelaria: um estudo na via costeira de Natal, RN. Caderno Virtual de Turismo. Rio de Janeiro, v. 11, n. 2., pp. 220-233, ago.

Artigo recebido em: 25/06/2015.

Artigo aprovado em: 27/07/2016.

\section{Nicole Cavalcanti Silva}

Universidade Federal de Campina Grande - UFCG - Mestranda do Programa de Pós-Graduação Interdisciplinar em Recursos Naturais PPGRN/CTRN/UFCG. Graduada em Administração de Empresas pela Universidade Federal de Campina Grande (UFCG). E-mail: nickolecavalcanti@gmail.com.

\section{Gesinaldo Ataíde Cândido}

Universidade Federal de Campina Grande - UFCG - Professor doutor do Programa de Pós-Graduação em Recursos Naturais da UFCG. E vinculado ao departamento de Administração da UFCG. Professor Titular do curso de Administração da UFCG. E-mail: gacandido@uol.com.br. 